\title{
Electronic markets and the future internet: from clouds to semantics
}

\author{
Ricardo Colomo-Palacios • Pedro Soto-Acosta • \\ T. Ramayah $\cdot$ Meir Russ
}

Published online: 1 May 2013

(C) Institute of Information Management, University of St. Gallen 2013

Internet entrepreneurs are dramatically changing the business environment since the late 1990s by revolutionizing how business processes and transactions are conducted all over the world. In this sense, business networking revenues are increasing exponentially and the number of products/services available online for businesses and consumers are also growing steadily. However, questions remain unanswered regarding whether and how new Internet technologies such as the so called social web, the semantic web and cloud computing will bring new forms of business networking, business value creation activities and business models. The social web can be defined as the second generation of community-driven web services (Social Networking Site, blogs, wikis, and others) where everyone can communicate, participate, collaborate and refine the information space (Colomo-Palacios 2010; Paroutis and Al Saleh 2009). In other words, the social web encompasses the design of websites and software to support and foster social interaction. Social web technologies have become not only key tools for information and knowledge management within firms (Valencia-García et al. 2010), but also a required tool for competition and interaction with customers across many industries. These web sites allow

\author{
R. Colomo-Palacios $(\square)$ \\ Universidad Carlos III de Madrid, Madrid, Spain \\ e-mail: ricardo.colomo@uc3m.es \\ P. Soto-Acosta \\ Universidad de Murcia, Murcia, Spain \\ e-mail: psoto@um.es \\ T. Ramayah \\ School of Management, Universiti Sains Malaysia, Penang, \\ Malaysia \\ e-mail: ramayah@usm.my \\ M. Russ \\ University of Wisconsin-Green Bay, Green Bay, WI, USA \\ e-mail: russm@uwgb.edu
}

knowledge creation and sharing by the interaction of employees and other stakeholders via blogs, wikis, forums and online social networks. At the same time, the potential of the social web has allowed firms not only to interact with customers but also to promote their products and services. In this sense, firms are more frequently adopting these new channels and technologies to improve their reputation and increase their market share. Shared ownership of brand, image and reputation are key benefits derived from the social Web (Jones and Iredale 2009).

Despite all the above mentioned benefits resulting from the implementation of Internet technologies, traditional websites are designed to be read by people, not machines. In this sense, the advent of the semantic web has emerged in the form of new promising tools for information and data engineering (Vossen et al. 2007). The term "semantic web" was coined by Berners-Lee et al. (2001), to describe the evolution from a document-based web toward a new paradigm that includes data and information for computers to manipulate. The semantic web facilitates computers' interpretation of information, so they can perform more of the tedious work involved in finding, combining, and acting upon information on the web (Soto-Acosta et al. 2010). In this sense, the semantic web is driving the evolution of the current web by enabling users to find, share, and combine information more easily. Still other Internet tools and services such as cloud computing are arising nowadays. Cloud computing involves the delivery of computing (shared resources and software) over the Internet as a service rather than as a product (Colomo-Palacios et al. 2012) In particular, cloud computing enables the transformation of Information Technology expenditure from a "capital expenditure" (requiring finances which may be difficult to raise) to a pay-as-you-go "operating expenditure" (Nikolov 2011). In this sense, cloud computing presents a number of potential benefits which are driving its adoption. Some of the 
frequently mentioned benefits include cost reduction, improved provisioning and access to resources beyond what would normally be possible by a single company (Grossman 2009). All these technologies may be affecting business networking and electronic markets today but also will surely influence tomorrow, since a large number of new services will be available to purchase online and new business models will arise to commercialize them.

The evolution of these new Internet technologies determines however, not only the redesign of the networking infrastructure and its services, but also the way in which businesses, consumers and governments interact electronically. This profound shift is bringing, among others, several challenges and issues related to security, trust, mobility or scalability. Thus, the research community must address the challenges, threats and opportunities of new Internet technologies and provide solutions and guidance to current and future managerial, social and legal issues. Our objective in this special issue is to contribute to the growing body of knowledge regarding new Internet technologies from an inter-disciplinary point of view.

After a competitive and thorough double-blind review process for this special issue, we are delighted to have accepted three high-quality papers out of a total of 11 submissions. Taken together, the three articles included in this special issue are interesting and advance our scholarly knowledge on new Internet technologies. They present a new idea for the acquisition of new customers in the business-to-business market using social networking, an empirical study on the barriers and effects of cloud computing adoption in small and medium-sized enterprises (SMEs), as well as a paper analyzing customer preferences among start-up companies for adopting cloud computing.

The first paper, entitled "New business client acquisition using social networking sites", by Przemyslaw Kazienko, Natalia Szozda, Tomasz Filipowski and Wieslaw Blysz, introduces a business-to-business market application called SCAN (System for Client Acquisition via Social Network), which enables the acquisition of customers via social networking sites. More specifically, the system supports sales managers in finding new potential clients through social networking sites. In contrast to existing business matching services, the SCAN system exploits companies' data repositories better and more efficiently. The proposed solution is particularly suitable for companies looking for new relationships with potential clients or contractors in the business market, where finding potential partners is crucial for companies' development.

The second work, entitled "Cloud computing in industrial SMEs: Identification of the barriers to its adoption and effects of its application", by Sara Trigueros-Preciado, Daniel PérezGonzález and Pedro Solana-González addresses the important issue of the adoption and implementation of cloud computing in industrial SMEs. Particularly, these authors investigate the degree of knowledge of cloud computing, barriers to its implementation and the results derived from the use of cloud computing in this specific type of organization. To achieve the paper's objectives the authors make use of qualitative and quantitative techniques. The qualitative study included two group meetings with 17 information technology managers from industrial SMEs in Cantabria (Northern Spain), while the quantitative study consisted of a questionnaire administered to 94 industrial SMEs from the same geographic area. The authors find that the knowledge of cloud computing by SMEs is very low, this certainly being the main barrier to its adoption. In addition, findings show that cost reduction, scalability and flexibility are the major value propositions obtained by adopters of cloud computing.

The third contribution, entitled "Cloud computing adoption: An empirical study of customer preferences among start-up companies", by Jonas Repschlaeger, Koray Erek and Ruediger Zarnekow, applies a multi-method approach to investigate which customer preferences exist among startup companies and which cloud provider properties are relevant to the success of the start-up companies. These properties are examined among 108 start-up companies from Germany, Europe and the United States and analyzed in three steps using factor analysis to define customer preferences, cluster analysis to identify customer segments, and discriminant analysis to validate the identified clusters. Findings from this study show that start-ups can be basically divided into five clusters each with certain requirements on cloud provider characteristics.

Lastly, while reviewing the papers for this special issue, an insight into potential areas for future research transpired, resulting from gaps identified by the editors of this special issue (using the strategic framework proposed by Russ et al. 2010). For markets to be effective and efficient, the industry value added chain must be well situated, transparent and well integrated (among other characteristics, see Malone et al. 1987). That being the case, a number of aspects was missing from the discussion. E-procurement would be one example (e.g., Panda and Sahu 2012). Supply chain and logistics is another aspect that should be included in the market analysis (e.g. Bask et al. 2012). A further aspect of potential study is the process aspect (see example of business process compliance in Becker et al. 2012). An enriched discussion including the aspects listed above (among others), can increase the profit pool of the markets and the understanding of value appropriation by the different players in the market (Gadiesh and Gilbert 1998; Gordon et al. 2012).

We would like to specially thank Karen Heyden, the Executive Editor of Electronic Markets, for the extraordinary support during the whole process and the authors and reviewers who contributed to make this special issue possible. 
We also extend our thanks to Hans-Dieter Zimmermann, Senior Editor, for his help in the last processes.

\section{The Guest Editors}

\section{References}

Bask, A., Lipponen, M., \& Tinnila, M. (2012). E-commerce logistics: a literature research review and topics for future research. International Journal of E-Services and Mobile Applications, 4(3), 1-22.

Becker, J., Delfmann, P., Eggert, M., \& Schwittay, S. (2012). Generalizability and applicability of model-based business process compliance-checking approaches-a state-of-the-art analysis and research roadmap. BuR Business Research Journal, 5(2), 221-247.

Berners-Lee, T., Hendler, J., \& Lassila, O. (2001). The semantic web. Scientific American, 284(5), 34-43.

Colomo-Palacios, R. (2010). Web 2.0: new and challenging practical issues. The Learning Organization, 17(6), 476-477.

Colomo-Palacios, R., Fernandes, E., Sabbagh, M., \& de AmescuaSeco, A. (2012). Human and intellectual capital management in the cloud: software vendor perspective. Journal of Universal Computer Science, 18(11), 1544-1557.

Gadiesh, O., \& Gilbert, J. L. (1998). How to map your industry's profit pool. Harvard Business Review, 76(3), 139-147.

Gordon, T., Shackel, R., \& Mark, S. (2012). Regulation of legal services in the e-world: a need to short circuit hot spots in ethics and novel practices? International Journal of the Legal Profession, 19(1), 55-87.

Grossman, R. (2009). The case for cloud computing. IT Professional, 11(2), 23-27.

Jones, B., \& Iredale, N. (2009). Entrepreneurship education and Web 2.0. Journal of Research in Marketing and Entrepreneurship, 11(1), 66-77.

Malone, T. W., Yates, J., \& Benjamin, R. I. (1987). Electronic markets and electronic hierarchies. Communications of the ACM, 30, 484- 497.

Nikolov, G. I. (2011). Cloud computing and government: Background, benefits, risks. New York: Nova.

Panda, P., \& Sahu, G. P. (2012). e-Procurement implementation: Critical analysis of the impact of success factors on project outcome. The IUP Journal of Supply Chain Management, 9(2), 44-72.

Paroutis, S., \& Al Saleh, A. (2009). Determinants of knowledge sharing using Web 2.0 technologies. Journal of Knowledge Management, 13(4), 52-63.

Russ, M., Fineman, R., \& Jones, J. K. (2010). C ${ }^{3}$ EEP Taxonomyknowledge based strategies. In M. Russ (Ed.), Knowledge management strategies for business development (pp. 133-158). Hershey: Business Science Reference.

Soto-Acosta, P., Casado-Lumbreras, C., \& Cabezas-Isla, F. (2010). Shaping human capital in software development teams. The case of mentoring enabled by semantics. IET Software, 4(6), 445-452.

Valencia-García, R., García-Sánchez, F., Castellanos-Nieves, D., Fernández-Breis, J. T., \& Toval, A. (2010). Exploitation of social semantic technology for software development team configuration. IET Software, 4(6), 373-385.

Vossen, G., Lytras, M., \& Koudas, N. (2007). Editorial: revisiting the (machine) semantic web: the missing layers for the human semantic web. IEEE Transactions on Knowledge and Data Engineering, 19(2), 145-148. 